\title{
Comparison of the efficacy of autogenous inactivated Porcine Reproductive and Respiratory Syndrome Virus (PRRSV) vaccines with that of commercial vaccines against homologous and heterologous challenges
}

Marc F Geldhof ${ }^{1 *}$, Merijn Vanhee ${ }^{2}$, Wander Van Breedam¹, Jan Van Doorsselaere ${ }^{2}$, Uladzimir U Karniychuk ${ }^{1}$ and Hans J Nauwynck ${ }^{*}$

\begin{abstract}
Background: The porcine reproductive and respiratory syndrome virus (PRRSV) is a rapidly evolving pathogen of swine. At present, there is a high demand for safe and more effective vaccines that can be adapted regularly to emerging virus variants. A recent study showed that, by the use of a controlled inactivation procedure, an experimental BEl-inactivated PRRSV vaccine can be developed that offers partial protection against homologous challenge with the prototype strain LV. At present, it is however not known if this vaccine can be adapted to currently circulating virus variants. In this study, two recent PRRSV field isolates (07 V063 and 08 V194) were used for BEl-inactivated vaccine production. The main objective of this study was to assess the efficacy of these experimental BEl-inactivated vaccines against homologous and heterologous challenge and to compare it with an experimental LV-based BEl-inactivated vaccine and commercial inactivated and attenuated vaccines. In addition, the induction of challenge virus-specific (neutralizing) antibodies by the different vaccines was assessed.

Results: In a first experiment (challenge with 07 V063), vaccination with the experimental homologous (07 V063) inactivated vaccine shortened the viremic phase upon challenge with approximately 2 weeks compared to the mock-vaccinated control group. Vaccination with the commercial attenuated vaccines reduced the duration of viremia with approximately one week compared to the mock-vaccinated control group. In contrast, the experimental heterologous (LV) inactivated vaccine and the commercial inactivated vaccine did not influence viremia. Interestingly, both the homologous and the heterologous experimental inactivated vaccine induced 07 V063-specific neutralizing antibodies upon vaccination, while the commercial inactivated and attenuated vaccines failed to do so.

In the second experiment (challenge with 08 V194), use of the experimental homologous (08 V194) inactivated vaccine shortened viremia upon challenge with approximately 3 weeks compared to the mock-vaccinated control group. Similar results were obtained with the commercial attenuated vaccine. The experimental heterologous (07 V063 and LV) inactivated vaccines did not significantly alter viremia. In this experiment, 08 V194-specific neutralizing antibodies were induced by the experimental homologous and heterologous inactivated vaccines and a faster appearance post challenge was observed with the commercial attenuated vaccine.

(Continued on next page)
\end{abstract}

\footnotetext{
* Correspondence: marc.geldhof@UGent.be; hans.nauwynck@UGent.be

'Laboratory of Virology, Faculty of Veterinary Medicine, Ghent University, Salisburylaan 133, Merelbeke 9820, Belgium

Full list of author information is available at the end of the article
} 
(Continued from previous page)

Conclusions: The experimental homologous inactivated vaccines significantly shortened viremia upon challenge. Despite the concerns regarding the efficacy of the commercial attenuated vaccines used on the farms where the field isolates were obtained, use of commercial attenuated vaccines clearly shortened the viremic phase upon challenge. In contrast, the experimental heterologous inactivated vaccines and the commercial inactivated vaccine had no or only a limited influence on viremia. The observation that homologous BEl-inactivated vaccines can provide a more or less standardized, predictable degree of protection against a specific virus variant suggests that such vaccines may prove useful in case virus variants emerge that escape the immunity induced by the attenuated vaccines.

\section{Background}

Porcine reproductive and respiratory syndrome virus (PRRSV) infection is characterized by reproductive failure in sows, and is associated with respiratory problems in pigs of all ages [1-7]. With few exceptions, PRRSV is present in a majority of swine-producing countries around the world and gives rise to significant economic losses in the swine industry [8]. Based on genetic and antigenic analysis, two PRRSV genotypes are recognized: a European (EU) genotype (prototype: Lelystad virus, LV) [9] and a North American (NA) genotype (prototype: VR2332), which share about 55-70\% nucleotide homology [10]. However, a high genetic variability has been demonstrated within both genotypes [10-13] and the genetic differences between virus variants are mirrored in different virulence, pathogenicity, immunogenicity, ... A recent study by Diaz et al. (2012) showed that infection with different PRRSV strains leads to different virological and immunological outcomes and results in different degrees of homologous and heterologous protection [14]. Another study by Martinez-Lobo and coworkers (2011) reported that different PRRSV isolates differ in their susceptibility to antibody neutralization [15]. Evidently, the high variability of the virus represents a major hurdle for effective PRRSV prevention and control [16]. Since PRRSV poses a serious burden on the swine industry worldwide, the need for efficient control measures is high. A variety of PRRS eradication strategies have been described, including total depopulation/repopulation, partial depopulation, segregated early weaning, test and removal and herd closure. Also planned exposure to a farm-specific virus isolate is a common strategy in the United States and Canada [17]. This last approach is often performed without monitoring and is consequently unreliable in getting the targeted population homogeneously infected in a timely manner. While the above strategies can certainly be useful, it is also clear that efficient PRRSV vaccines are extremely valuable tools to minimize the clinical and economical impact of PRRSV infections. However, the commonly used vaccines, both attenuated and inactivated, are not without their problems. Although attenuated vaccines have the potential to protect animals against viremia, the degree of protection depends on various factors, including the homology between the vaccine virus and the circulating virus [18]. In addition, there are some safety concerns, as the vaccine virus may spread and revert to virulence [19-22]. The commercially available inactivated vaccines are generally safe to use, but do not provide sufficient protection $[21,23,24]$. In addition, the ability of PRRSV to subvert the host immune system further complicates these matters. At present, it is generally accepted that there is a need for new and safe vaccines that can protect against infection with those virus variants that escape immunity induced by the currently available commercial vaccines. In this context, the use of vaccine virus that is homologous to the PRRSV variants prevalent in the herd seems to be favourable [18]. Vanhee et al. (2009) demonstrated that, by use of a controlled inactivation procedure and a suitable adjuvant, an LV-based inactivated PRRSV vaccine can be developed that systematically induces an LV-specific virus-neutralizing (VN) antibody response upon 2 vaccinations in naïve piglets. Following homologous challenge of the vaccinated pigs with $\mathrm{LV}$, animals developed an earlier and strongly elevated $\mathrm{VN}$ antibody response and a significant reduction of viremia was observed [25]. Currently however, it is unknown whether it is possible to achieve similar results for PRRSV isolates that are currently causing reproductive or respiratory disorders in the field. Two recent PRRSV isolates, from outbreaks in herds vaccinated with a registered vaccine, were used for autogenous inactivated vaccine development. The main objective of this study was to test the capacity of experimental inactivated autogenous PRRSV vaccines to protect naïve pigs against homologous PRRSV challenge and to compare the efficacy of these vaccines with that of experimental heterologous inactivated vaccines, the commercial vaccine used on the farms, and other commercial inactivated and attenuated vaccines.

\section{Results}

\section{Vaccination experiment with PRRSV isolate 07 V063 Clinical examination}

All animals remained in good health after they were vaccinated. No local or systemic vaccine side effects were 
noted throughout the trial period. No pigs died during the entire experimental period. Body temperatures fluctuated in all groups and statistically significant differences were not detected. Challenge with PRRSV isolate 07 V063 induced moderate fever (higher than $39.5^{\circ} \mathrm{C}$, but not higher than $40.6^{\circ} \mathrm{C}$ ) within 10 days post infection in 32 out of 36 inoculated pigs. The 4 remaining animals did not develop fever. By 11 days post challenge, fever had disappeared in all animals.

\section{Viremia}

Upon challenge, all animals became viremic. In the adjuvant control group (group CON), viremia was detected from day 1 after the challenge ( 3 pigs out of 6 ) and peaked around 10 days post challenge (dpc), with a mean virus titer of $3.6 \log _{10} \mathrm{TCID}_{50} / \mathrm{mL}$. Viremia had cleared in all animals by 5 weeks post challenge (Figure $1, \mathrm{CON}$ ). In the binary ethyleneimine (BEI) inactivated 07 V063 group (group $07 \mathrm{V063i}$ ), all animals became viremic, but the peak viremia occurred earlier (day 5) and was lower $\left(2.9 \log _{10} \mathrm{TCID}_{50} / \mathrm{mL}\right)$. From $10 \mathrm{dpc}$, virus was no longer detected in the serum of any of the animals, but one animal was again viremic at day 21 post challenge (Figure 1, 07 V063i). The mean viral titer in the serum was significantly reduced compared to the control group at days 10 and $14(\mathrm{p}<0.05)$. In group $07 \mathrm{V063i}$, a significantly lower number of viremic piglets was observed compared to group $\mathrm{CON}$ on days 10 and 14 post challenge $(\mathrm{p}<0.05)$. In the BEI-inactivated LV vaccinated group (group LVi), all animals became viremic after challenge, with a peak viremia of $3.6 \log _{10} \mathrm{TCID}_{50} / \mathrm{mL}$ on day 7 . Four weeks post challenge, virus was not found anymore in the serum of any of the 6 pigs (Figure 1, LVi). The virus titers were not significantly lower than those of group CON. In the group vaccinated with Progressis ${ }^{\circledR}$ (group PROi), viremia was detected in all animals, with a peak of $3.6 \log _{10} \mathrm{TCID}_{50} /$ $\mathrm{mL}$ around $10-14 \mathrm{dpc}$. The viremic phase showed a similar pattern as in group $\mathrm{CON}$ and virus titers were not significantly reduced. Viremia disappeared in all animals by 5 weeks after challenge (Figure 1, PROi). In the group vaccinated with a single shot of Porcilis ${ }^{\circledR}$ PRRS (group PORatt) and the group vaccinated with one dose of Ingelvac ${ }^{\circledR}$ PRRS (group INGatt), a partial reduction in viremia was seen. Viremia peaked at $5 \mathrm{dpc}$ with average titers of $3.3 \log _{10} \mathrm{TCID} 50 / \mathrm{mL}$ (group PORatt) and $3.2 \log _{10}$ $\mathrm{TCID}_{50} / \mathrm{mL}$ (group INGatt) (Figure 1, PORatt and INGatt). No significant differences in mean virus titers were detected at any time-point between groups PORatt, INGatt and CON. Only at 5 weeks after challenge, all animals of these groups were consistently virus negative. Taking all data on viremia together, group 07 V063i was the only group that showed a significantly shortened viremia and a significant decrease in the number of viremic piglets compared to the mock-vaccinated control group.

\section{V063-specific antibodies}

In group $\mathrm{CON}$, virus-specific antibodies were not detected before challenge (Figure 2, CON). At $7 \mathrm{dpc}$, antibodies could be detected in all animals of this control group. In 2 animals of group $07 \mathrm{V063i}$, antibodies could already be detected at 3 weeks after the primo vaccination. The remaining animals within this group became seropositive after booster vaccination. From the first week after booster vaccination until 10 days after challenge, antibody titers in this group remained significantly higher than in group CON $(\mathrm{p}<0.05)$ (Figure 2, 07 V063i). In group LVi, virus-specific antibodies against 07 V063 were detected from 2 weeks after primo vaccination and all animals seroconverted after booster vaccination. Virus-specific antibody titers were significantly higher in group LVi compared to group CON from 7 days post booster vaccination until $21 \mathrm{dpc}$ and at $42 \mathrm{dpc}(\mathrm{p}<0.05)$ (Figure 2, LVi). In group PROi, one animal became seropositive at 1 week after booster vaccination, while the remaining animals did not show antibodies before challenge (Figure 2, PROi). Post challenge, the course of the antibody response of this group was similar as in group CON. In group PORatt, virusspecific antibodies were detected in 3 out of 6 pigs at 2 weeks after vaccination (Figure 2, PORatt). At 3 weeks post vaccination, all animals were seropositive. Virusspecific antibodies remained present during the entire experiment, and the antibody titers were significantly higher compared to group $\mathrm{CON}$ from 21 days post vaccination until $21 \mathrm{dpc}(\mathrm{p}<0.05)$. In group INGatt, virusspecific antibodies were found in 3 out of 6 pigs at 2 weeks after vaccination (Figure 2, INGatt). One week later, all pigs had seroconverted and remained seropositive until the end of the experiment. Antibody titers were significantly higher compared to group CON from 21 days post vaccination till $5 \mathrm{dpc}$. Taken together, the courses of the IPMA antibody titers in all groups were similar to those described in other studies [24,25].

\section{V063-specific virus-neutralizing antibodies}

In group $\mathrm{CON}, \mathrm{VN}$ antibodies were not detected until 5 weeks post challenge. Even at 6 weeks post challenge, not all the animals from this group were positive for $\mathrm{VN}$ antibodies (Figure 3, CON). In group $07 \mathrm{V063i}$, 07 V063-specific VN antibodies were already detected upon booster vaccination. The mean $\mathrm{VN}$ antibody titer decreased immediately post challenge, but increased again 10 days after infection. Some animals had no or undetectable VN antibodies in the period between 2 weeks before and $10 \mathrm{dpc}$, but after this period, $\mathrm{VN}$ antibodies were detected in all animals. The mean $\mathrm{VN}$ antibody titer was significantly higher compared to group $\mathrm{CON}$ in the period between 1 week after booster vaccination and 5 weeks post challenge, reaching mean values ranging from 1.1 to 


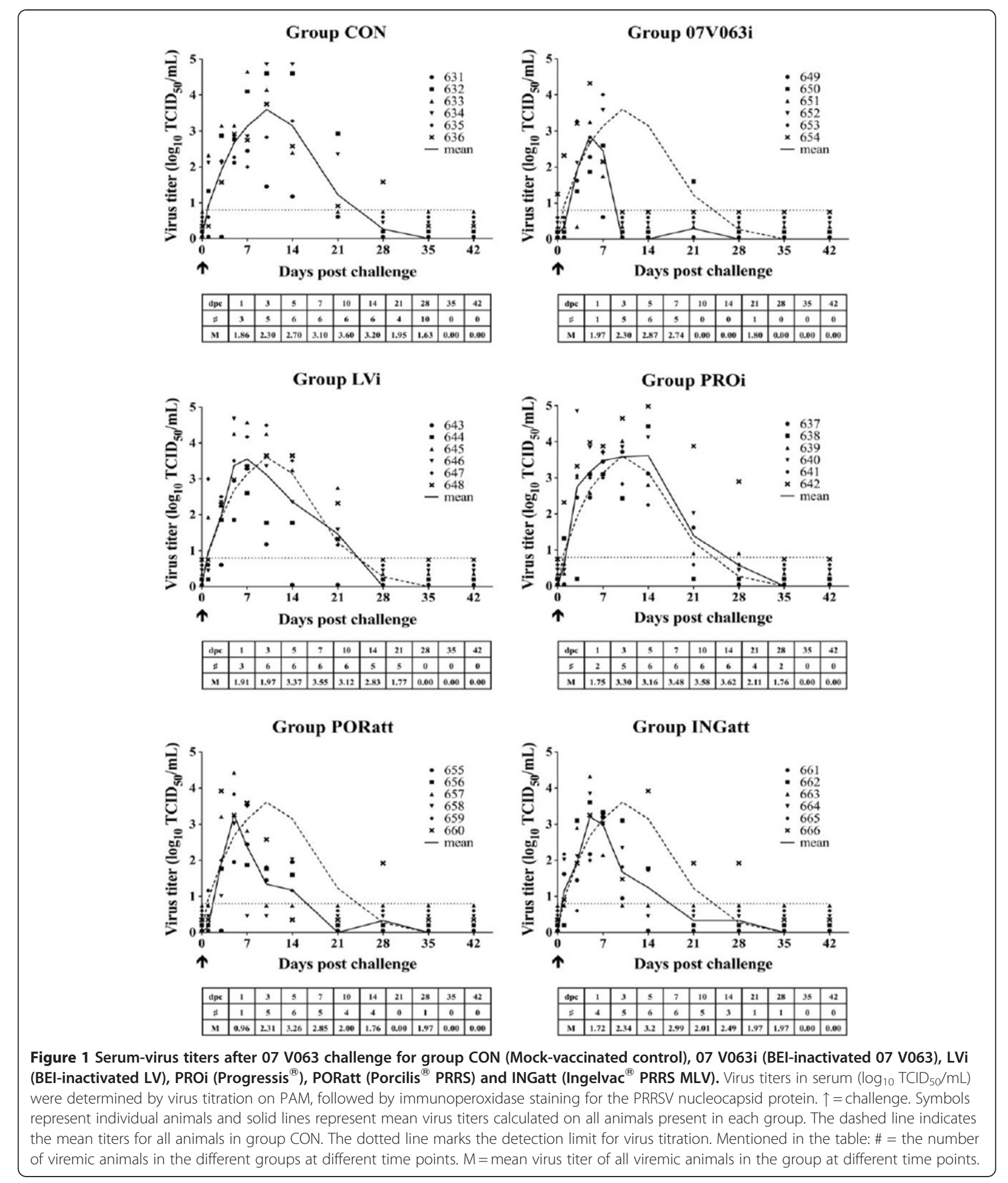

$4.2 \log _{2}(\mathrm{p}<0.05)$ (Figure 3, 07 V063i). A similar pattern was observed in group LVi: 07 V063-neutralizing antibodies were already detected at 1 week after booster vaccination. VN antibody titers initially decreased post challenge and increased again from $10 \mathrm{dpc}$. Some animals turned negative for $\mathrm{VN}$ antibodies in the period between 1 week before and 10 days after the challenge, but after this period, $\mathrm{VN}$ antibodies were detected in all 6 animals. Remarkably, one animal in this group did not show neutralizing antibodies earlier than 4 weeks post challenge. 


\section{Group CON}

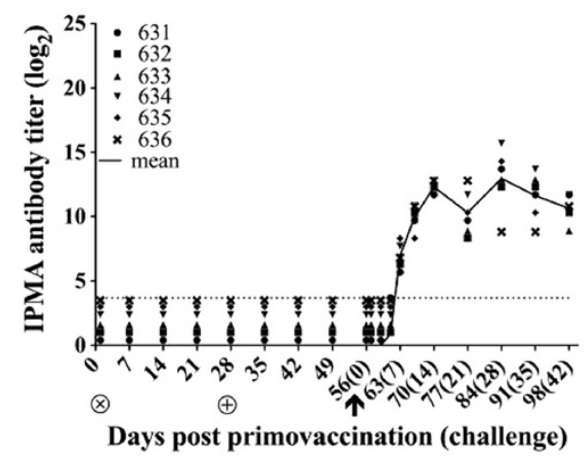

Group LVi

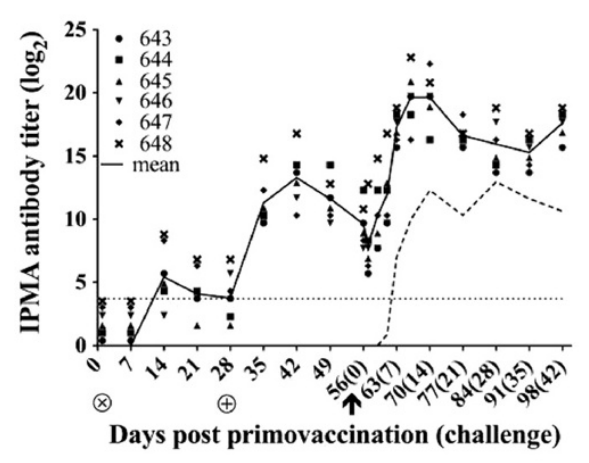

Group PORatt

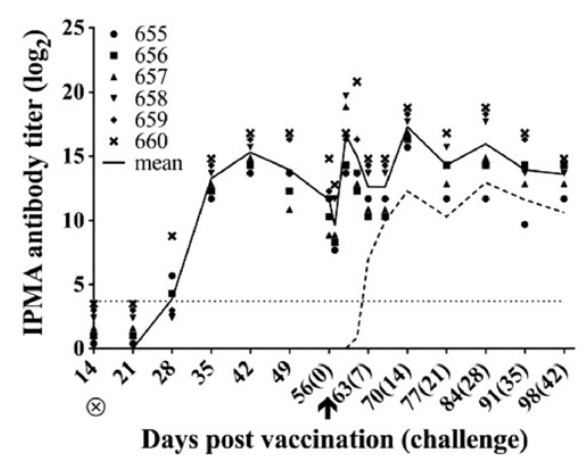

Group 07V063i

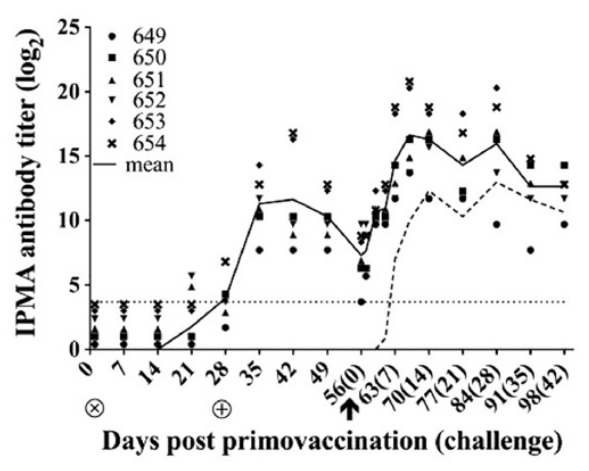

Group PROi

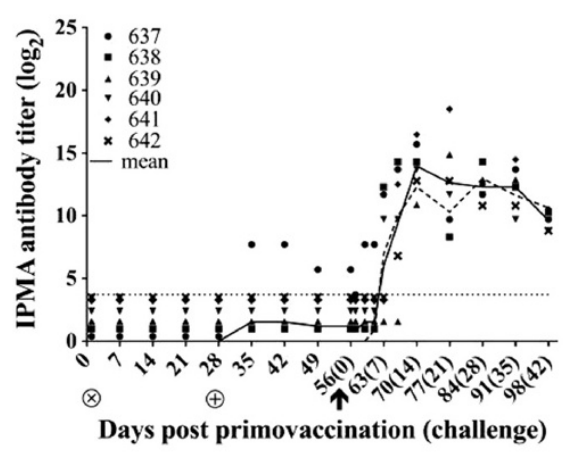

Group INGatt

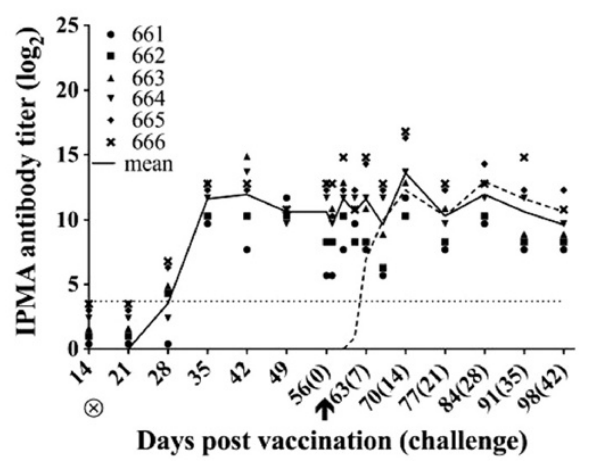

Figure 207 V063-specific IPMA antibody titers $\left(\log _{2}\right)$ after vaccination and 07 V063 challenge for group CON (Mock-vaccinated control), 07 V063i (BEl-inactivated 07 V063), LVi (BEl-inactivated LV), PROi (Progressis ${ }^{\circledR}$ ), PORatt (Porcilis ${ }^{\circledR}$ PRRS) and INGatt (Ingelvac ${ }^{\circledR}$ PRRS MLV). $\otimes$ = primo vaccination; $\oplus=$ booster vaccination; $\uparrow=$ challenge. Symbols represent individual animals and solid lines represent mean IPMA titers calculated on all animals present in each group. The dashed line indicates the mean titers for all animals in group CON. The dotted line marks the detection limit for the IPMA test.

The VN antibody titers were significantly higher compared to the control group at 1 and 2 weeks after booster vaccination and at 10 and $14 \mathrm{dpc}$, reaching mean values of 3.5 , 3.1, 1.9 and $2.3 \log _{2}$, respectively $(\mathrm{p}<0.05)$ (Figure $3, \mathrm{LVi}$ ). Pigs that were vaccinated with Progressis ${ }^{\circledR}$ (two shots), Porcilis ${ }^{\circledR}$ PRRS (single shot) and Ingelvac ${ }^{\circledR}$ PRRS (single shot) showed a roughly similar VN antibody response as the animals in the control group. In the Porcilis $^{\circledR}$ vaccinated group, a slight increase of $\mathrm{VN}$ antibodies was noticed at 5 weeks post challenge, but there were no significant differences with group CON (Figure 3, PORatt). In summary, both BEI-inactivated vaccines induced a strong 07 V063-specific VN antibody response after booster vaccination, while the commercial vaccines, both inactivated and attenuated (EU or NA genotype), did not induce a VN antibody response against $07 \mathrm{~V} 063$. 


\section{Group CON}

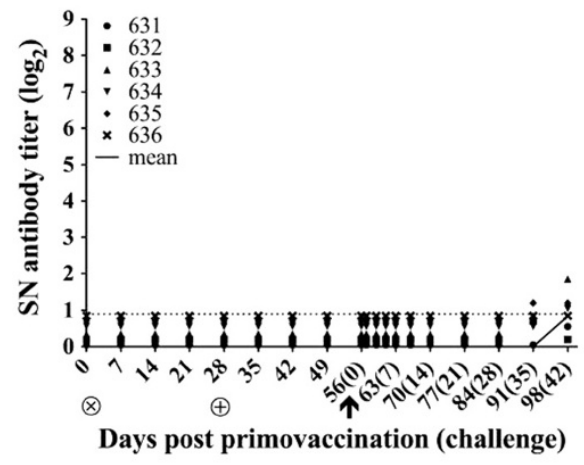

Group LVi

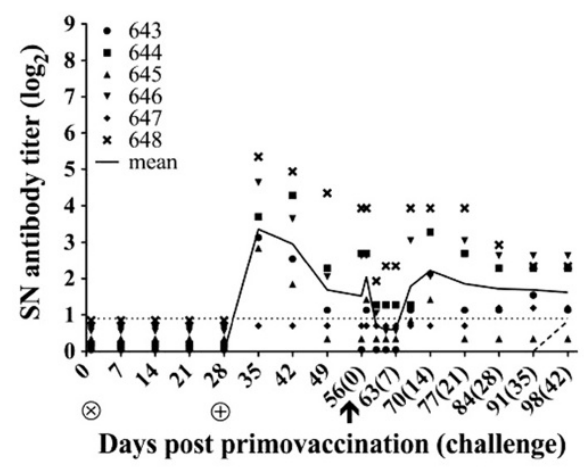

Group PORatt

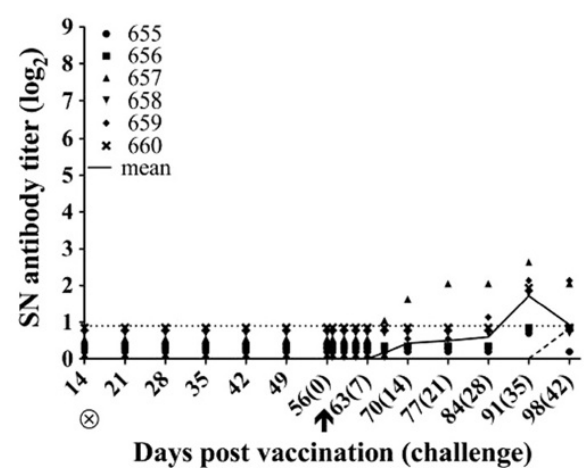

\section{Group 07V063i}

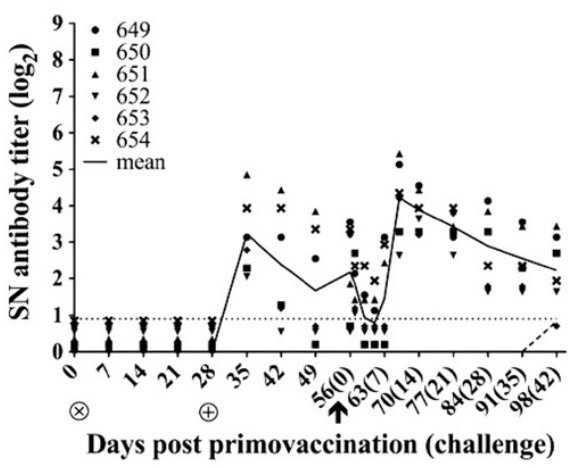

Group PROi

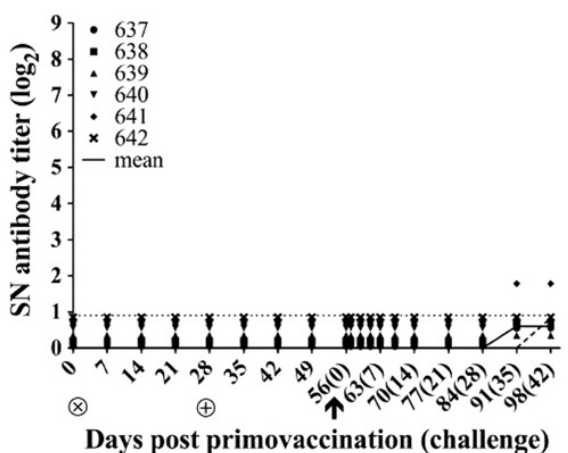

Group INGatt

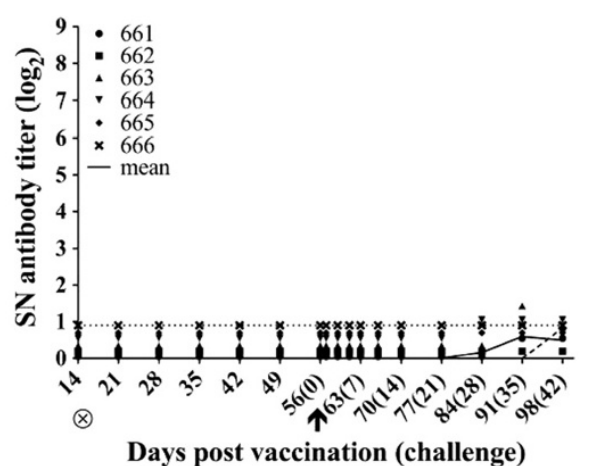

Figure 307 V063-neutralizing antibody titers $\left(\log _{2}\right)$ after vaccination and 07 V063 challenge for group CON (Mock-vaccinated control), 07 V063i (BEl-inactivated 07 V063), LVi (BEl-inactivated LV), PROi (Progressis ${ }^{\circledR}$ ), PORatt (Porcilis ${ }^{\circledR}$ PRRS) and INGatt (Ingelvac ${ }^{\circledR}$ PRRS MLV). $\otimes$ = primo vaccination; $\oplus=$ booster vaccination; $\uparrow=$ challenge. Symbols represent individual animals and solid lines represent mean SN titers calculated on all animals present in each group. The dashed line indicates the mean titers for all animals in group CON. The dotted line marks the detection limit for the SN test.

Vaccination experiment with PRRSV isolate 08 V194

\section{Clinical examination}

All animals remained in good health after they were vaccinated. No local or systemic vaccine side effects were noted throughout the trial period. One pig of group PORatt2 died at day 84 at the moment of blood collection. The daily rectal temperatures varied in all groups and no statistically significant differences were observed. Challenge with PRRSV isolate 08 V194 induced moderate fever (higher than $39.5^{\circ} \mathrm{C}$, but not higher than $40.4^{\circ} \mathrm{C}$ ) within 7 days post infection in 24 out of 31 inoculated pigs. The 7 remaining animals did not develop fever. By 8 days post challenge, fever had disappeared in all animals.

\section{Viremia}

Upon challenge, all animals became viremic. In the control group (group CON2), a maximum mean virus titer of $3.8 \log _{10} \quad \mathrm{TCID}_{50} / \mathrm{mL}$ was reached at $10 \mathrm{dpc}$. 
Subsequently, a decline in virus titer was observed and virus was no longer detectable in the serum at 4,5 or 6 weeks after challenge, depending on the animal. Still, 1 piglet remained virus positive till 6 weeks post challenge (Figure 4, CON2). In the BEI-inactivated 08 V194 vaccinated group (group $08 \mathrm{~V} 194 \mathrm{i}$ ), the viremic peak at day 5 was not reduced compared to group $\mathrm{CON} 2$, but the mean virus titer at day 14 was significantly reduced $(\mathrm{p}<0.05)$ and from $21 \mathrm{dpc}$, virus could no longer be detected in any of the piglets (Figure 4, 08 V194i). The number of viremic piglets in group 08 V194i was significantly lower compared to group CON2 on day 21 and 28 post challenge $(\mathrm{p}<0.05)$. Mean virus titers in the group vaccinated with BEI-inactivated LV virus (group LVi2) were comparable to those in group CON2, reaching $3.0 \log _{10} \mathrm{TCID}_{50} / \mathrm{mL}$ at $10 \mathrm{dpc}$, and no significant differences could be detected at any time-point between group LVi2 and group CON2. For 3 animals of this group, virus was cleared from the blood at 3 weeks, for 2 others at 4 weeks and in the remaining animal at 5 weeks post challenge (Figure 4, LVi2). In the BEI-inactivated 07 V063 vaccinated group (group 07 V063i2), viremia was detected in all animals, with a peak around 5-10 dpc. The viremic phase showed a similar pattern as for group LVi2 and viremia was also not significantly reduced compared to group CON2. Viremia disappeared in all animals by 5 weeks after challenge (Figure 4, 07 V063i2). The mean virus titer in the group vaccinated with Porcilis $^{\circledR}$ PRRS (group PORatt2) reached $2.7 \log _{10} \mathrm{TCID}_{50} / \mathrm{mL}$ at 3 days and $2.5 \log _{10} \mathrm{TCID}_{50} / \mathrm{mL}$ at $5 \mathrm{dpc}$, but virus titers were not significantly different from those in group CON2 at these time points. At later time points however, virus titers were significantly reduced compared to group CON2 $(\mathrm{p}<0.05)$. Moreover, viremia in group PORatt2 was already cleared at $10 \mathrm{dpc}$ for 3 animals and at $28 \mathrm{dpc}$, all animals were negative (Figure 4, PORatt2). From 14 till $28 \mathrm{dpc}$, the total number of viremic animals in group PORatt2 was significantly lower than in group CON2 $(\mathrm{p}<0.05)$. In summary, groups $08 \mathrm{~V} 194 \mathrm{i}$ and PORatt2 showed a significantly shortened viremia and a significant decrease in the number of viremic piglets compared to the mock-vaccinated control group, while no such effect was seen in groups LVi2 and 07 V063i2.

\section{V194-specific antibodies}

All CON2 animals had virus-specific serum antibodies starting from $7 \mathrm{dpc}$ (Figure 5, CON2). All 6 animals of group 08 V194i seroconverted at 2 or 3 weeks after the first vaccination. Similarly, all animals of group LVi2 showed virus-specific antibodies 2 weeks after the first vaccination. In group 07 V063i2, 08 V194-specific antibodies were detected from 2 weeks after primo vaccination and all animals seroconverted after booster vaccination. Antibody titers in all 3 vaccinated groups were significantly higher compared to group CON2 from 1 week after booster vaccination up till $21 \mathrm{dpc}(\mathrm{p}<0.05)$ (Figure 5, 08 V194i, LVi2 and 07 V063i2). After $21 \mathrm{dpc}$, mean antibody titers in groups 08 V194i, LVi2 and 07 V063i2 remained higher compared to the control group, although differences were not significant. In group PORatt2, all pigs showed positive antibody titers at 2 weeks after vaccination; the antibody titers were significantly higher compared to group CON2 starting from 2 weeks after vaccination up till 3 weeks post challenge $(\mathrm{p}<0.05)$ (Figure 5, PORatt2). In summary, the course of the IPMA antibody titers in all groups were similar to those described in previous studies and the former experiment in this study $[24,25]$.

\section{V194-specific virus-neutralizing antibodies}

Starting from $21 \mathrm{dpc}, 3$ pigs of group CON2 showed a VN antibody titer and by $35 \mathrm{dpc}, \mathrm{VN}$ antibodies had appeared in all mock-vaccinated pigs (Figure 6, CON2). All six pigs of group $08 \mathrm{~V} 194 \mathrm{i}$ showed high VN antibody titers at 1 week after the booster vaccination and this remained so until the end of the experiment (Figure 6, 08 V194i). VN antibody titers were significantly higher in group $08 \mathrm{~V} 194 \mathrm{i}$ compared to group CON2 from 1 week after booster vaccination until 5 weeks post challenge, with mean values ranging from 3.2 to $6.2 \log _{2}(\mathrm{p}<0.05)$. All animals of group LVi2 seroconverted for VN antibodies at least once within 3 weeks after booster vaccination, but VN antibody titers remained low and were only significantly higher than group CON2 at $14 \mathrm{dpc}$, reaching a mean value of $2.6 \log _{2}(\mathrm{p}<0.05)$ (Figure 6, LVi2). A similar pattern as in group 08 V194i was observed in group 07 V063i2, where 08 V194-neutralizing antibodies could already be detected at 1 week after booster vaccination. Two animals turned negative for $\mathrm{VN}$ antibodies in the period between 2 weeks post booster vaccination and $10 \mathrm{dpc}$, but after this period, $\mathrm{VN}$ antibodies were consistently detected in all 6 animals. The mean VN antibody titer in group 07 V063i2 was significantly higher compared to group CON2 in the period between 1 week after booster vaccination and 4 weeks post challenge (except for time-point $5 \mathrm{dpc}$ ), reaching mean values ranging from 2.1 to $4.7 \log _{2}(\mathrm{p}<0.05)$ (Figure 6, 07 V063i2). None of the animals in group PORatt2 showed 08 V194-specific VN antibodies before challenge, but $\mathrm{VN}$ antibodies already appeared between 5 and 10 dpc. The mean VN antibody titer in group PORatt2 was slightly but not significantly higher compared to group CON2 between 7 and $14 \mathrm{dpc}$, reaching a maximum of $1.6 \log _{2}$ at $14 \mathrm{dpc}$ (Figure 6, PORatt2). In summary, both BEI-inactivated 08 V194 (homologous) and 07 V063 (heterologous) vaccines induced a strong 08 V194-specific $\mathrm{VN}$ antibody response upon booster vaccination, while this was not the case for the heterologous BEI-inactivated $\mathrm{LV}$ vaccine and the commercial attenuated vaccine. 


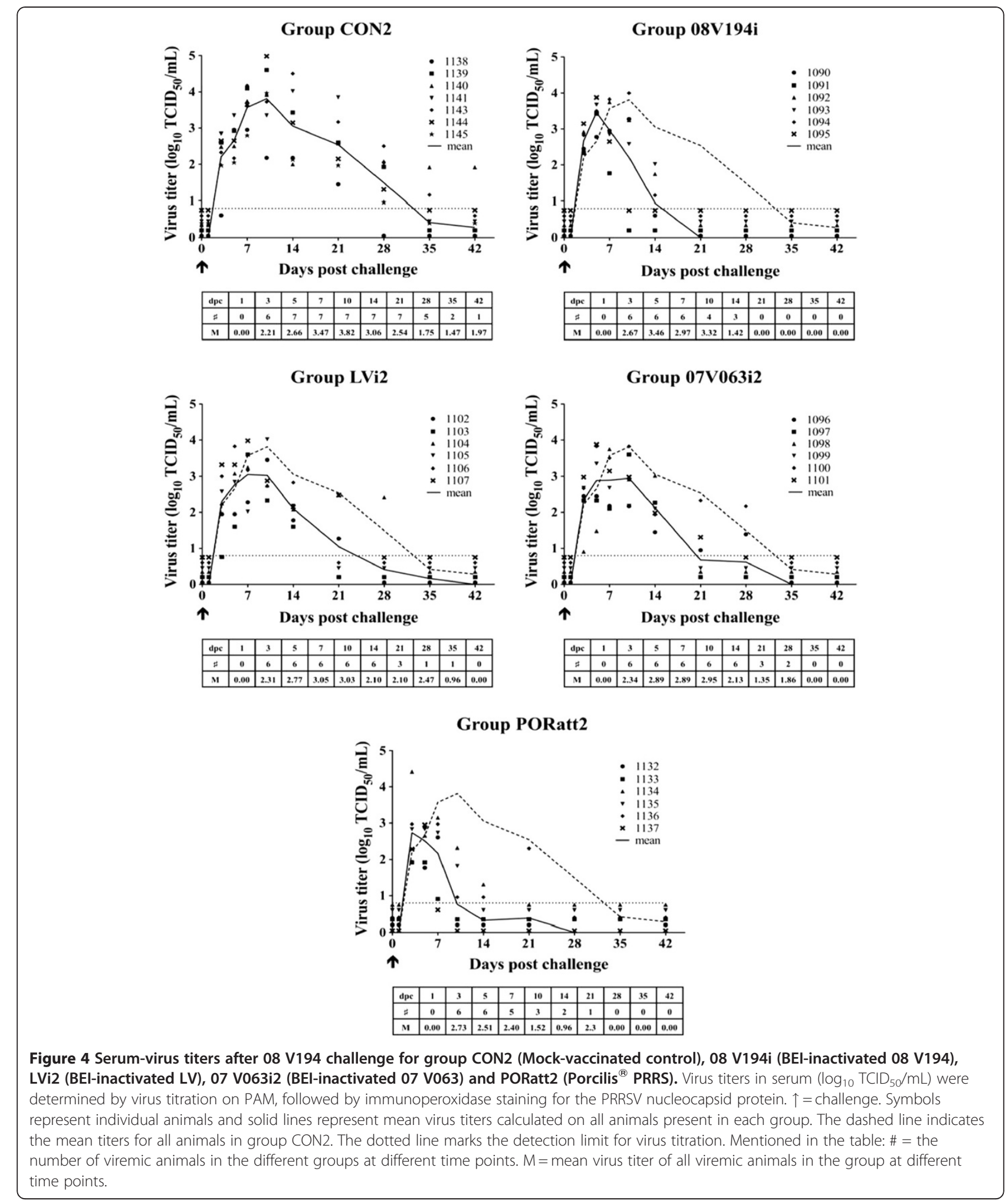

\section{Discussion}

PRRSV causes severe reproductive disorders in sows and boars and is associated with the porcine respiratory disease complex. The virus is difficult to control and has become endemic in many major swine-producing countries, leading to tremendous economic losses worldwide [8]. To control the disease, several commercial attenuated and inactivated vaccines are currently available. 


\section{Group CON2}

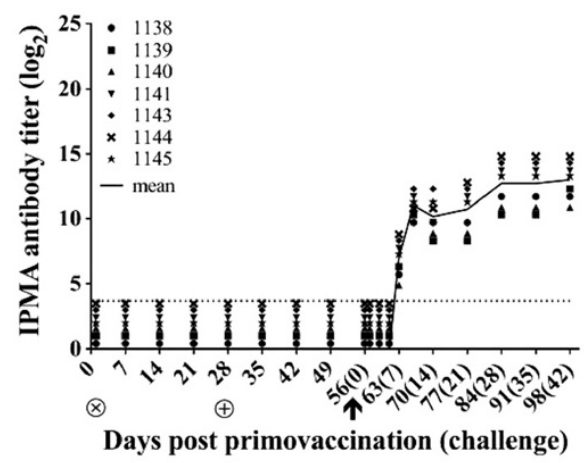

Group LVi2

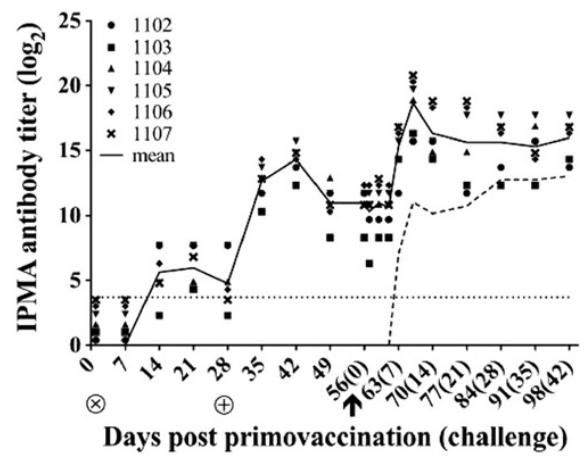

Group 08V194i

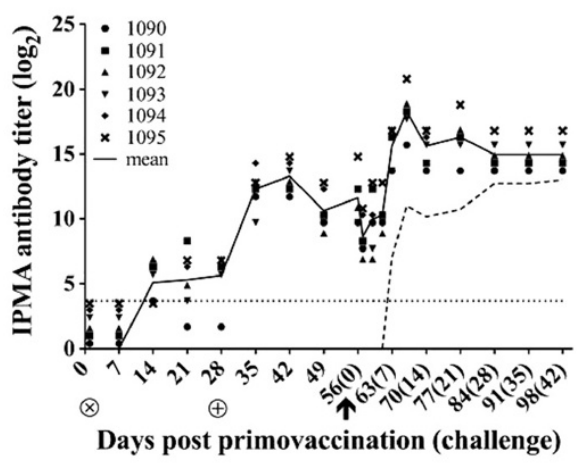

Group 07V063i2

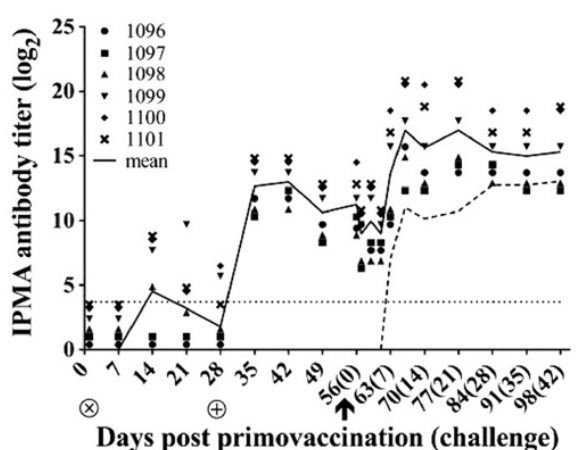

Group PORatt2

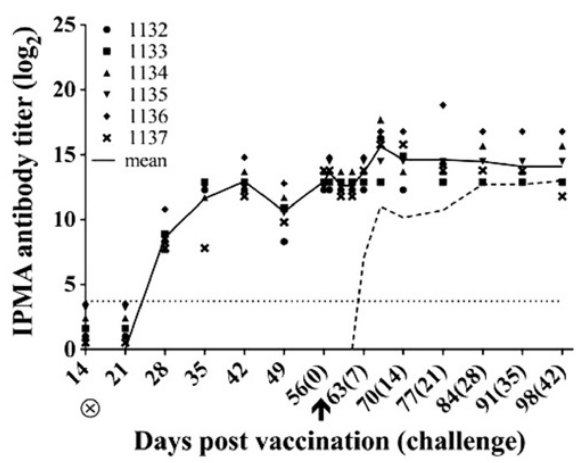

Figure 508 V194-specific IPMA antibody titers $\left(\log _{2}\right)$ after vaccination and 08 V194 challenge for group CON2 (Mock-vaccinated control), 08 V194i (BEl-inactivated 08 V194), LVi2 (BEl-inactivated LV), 07 V063i2 (BEl-inactivated 07 V063) and PORatt2 (Porcilis ${ }^{\circledR}$ PRRS). $\otimes=$ primo vaccination; $\oplus=$ booster vaccination; $\uparrow=$ challenge. Symbols represent individual animals and solid lines represent mean IPMA titers calculated on all animals present in each group. The dashed line indicates the mean titers for all animals in group CON2. The dotted line marks the detection limit for the IPMA test.

However, when used in the field, these vaccines have met with variable degrees of success. Reported outbreaks of clinical PRRS in vaccinated pigs have led to doubts about the efficacy of currently available vaccines [26]. New vaccination strategies are needed to achieve the goals of local and regional elimination of PRRSV and it is generally accepted that a continuous update of vaccine strains is necessary to reach an acceptable level of protection in the field, even within geographical areas of limited size. A recent study by Vanhee et al. (2009) [25] showed that a PRRSV LV-based BEI-inactivated vaccine induces LV-specific VN antibodies in PRRSV-negative animals and offers partial protection upon homologous challenge. In that study, it was however not assessed if such a vaccine can be adapted to field variants of PRRSV that are genetically and antigenically divergent from the 


\section{Group CON2}

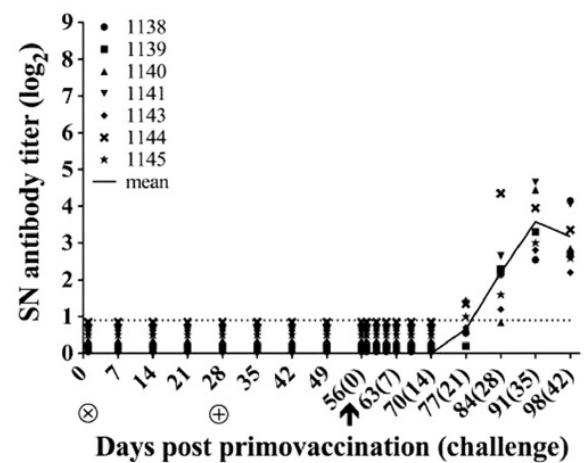

Group LVi2

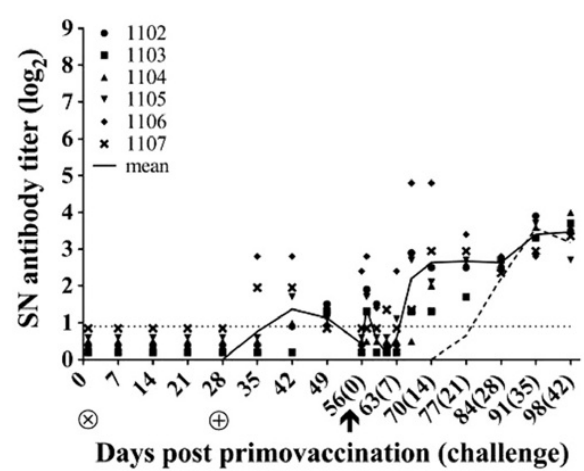

Group 08V194i

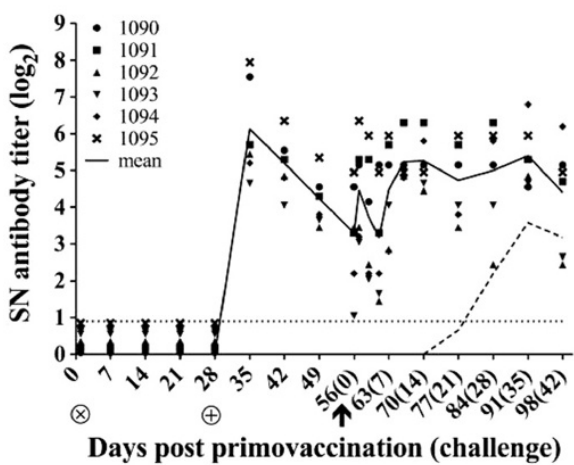

Group 07V063i2

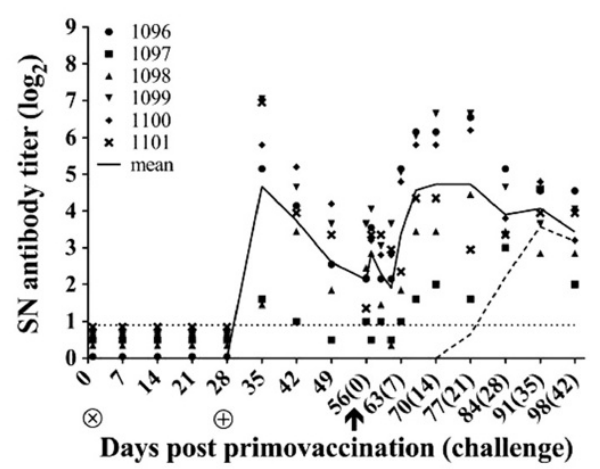

Group PORatt2

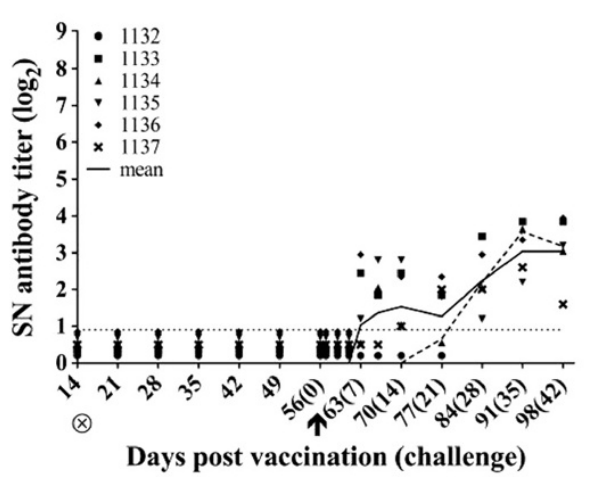

Figure 608 V194-neutralizing antibody titers $\left(\log _{2}\right)$ after vaccination and 08 V194 challenge for group CON2 (Mock-vaccinated control), 08 V194i (BEl-inactivated 08 V194), LVi2 (BEl-inactivated LV), 07 V063i2 (BEl-inactivated 07 V063) and PORatt2 (Porcilis ${ }^{\circledR}$ PRRS). $\otimes=$ primo vaccination; $\oplus=$ booster vaccination; $\uparrow=$ challenge. Symbols represent individual animals and solid lines represent mean SN titers calculated on all animals present in each group. The dashed line indicates the mean titers for all animals in group CON2. The dotted line marks the detection limit for the SN test.

currently used vaccine strains. The main objective of the current study was to assess the efficacy of experimental BEI-inactivated vaccines, based on recent PRRSV field isolates (07 V063 and 08 V194), against homologous and heterologous challenge. A commercial inactivated (Progressis $^{\circledR}$ ) and two commercial attenuated (Porcilis $^{\circledR}$ PRRS and Ingelvac ${ }^{\circledR}$ PRRS MLV) PRRSV vaccines were included in the study and served as a reference. Vaccine efficacy was assessed by evaluating the viremia upon challenge - a factor directly linked with viral pathogenesis and spread.

The 07 V063- and 08 V194-based inactivated PRRSV vaccines were effective in partially protecting naïve pigs upon homologous challenge. They shortened viremia with 2 (07 V063) and 3 (08 V194) weeks compared to the viremic phase in the respective mock-vaccinated 
groups, which lasted roughly 1 month. BEI-inactivated $L V$ vaccines were included to assess the impact of strain variability on vaccine efficacy. We found no reduction in 07 V063 viremia after the use of an inactivated LV-based vaccine and only a non-significant reduction of viremia upon challenge with 08 V194. Similarly, a 07 V063based BEI-inactivated PRRSV vaccine did not significantly reduce viremia upon challenge with the 08 V194 isolate. The Progressis ${ }^{\circledR}$ vaccine did not provide any virological protection, since viremia was observed for 4 weeks upon challenge with the 07 V063 isolate. This is in line with the results from previous studies, showing that the commercial inactivated vaccines appear not to influence viremia, even in nearly homologous conditions $[21,24,27]$. Vaccination with the EU-genotype attenuated vaccine reduced the duration of viremia upon challenge with 07 V063 with approximately one week. In animals challenged with $08 \mathrm{~V} 194$, this vaccine shortened viremia from 5 to 2 weeks. The NA-genotype attenuated vaccine reduced viremia in 07 V063-challenged animals with approximately one week. Hence, despite the concerns regarding the efficacy of the attenuated vaccine used on both farms, the results of our study indicate that the use of this vaccine in PRRS-naïve pigs can clearly limit viremia. These results are in line with earlier studies published by Cano et al. (2007) [28] and Scortti et al. (2006) [29], showing that attenuated vaccines can be successful in controlling and reducing clinical disease upon homologous and heterologous challenge.

In the field, PRRSV vaccination is mainly performed in sows. Therefore, we reasoned it would also be interesting to assess the antibody response induced by the vaccines, since maternal antibodies play a pivotal role in the passive (colostral) immunity that protects piglets during their first weeks of life [30]. Although resolution of PRRSV infection is not always directly correlated with the neutralizing antibody response [31], there is ample evidence that neutralizing antibodies can facilitate virus clearance and, when present in sufficient amounts, may even provide a sterilizing immunity [32-35]. IPMA and $\mathrm{SN}$ tests were performed to evaluate the capacity of the vaccines to induce or prime a challenge virus-specific (neutralizing) antibody response.

Vaccination with BEI-inactivated 07 V063 or 08 V194 vaccines consistently induced sizable titers of homologous PRRSV-neutralizing antibodies after at least two immunizations given four weeks apart. Interestingly, vaccination with BEI-inactivated $\mathrm{LV}$ also induced sizeable titers of 07 V063-neutralizing antibodies. Similarly, both 07 V063- and LV-based vaccines induced 08 V194-neutralizing antibodies, with the LV-induced titers being lower than the 07 V063-induced titers. In all groups vaccinated with a BEI-inactivated vaccine, the $\mathrm{VN}$ titers dropped immediately after challenge, which may indicate that the antibodies were consumed during their interaction with virus early in infection. However, after this initial drop in VN antibody titers, VN antibodies quickly reappeared. The fast appearance of $\mathrm{VN}$ antibodies upon challenge is in agreement with the findings in the study of Vanhee et al. (2009) [25] and demonstrates the potential of priming the neutralizing antibody response by immunization with a high dose of inactivated PRRSV. Although it has been reported that the PRRSV-specific neutralizing antibody response is to a large extent strain-specific and a lack in crossneutralization may occur even between genetically closely related virus strains [36,37], our data show that cross-neutralization between genetically different isolates can occur. In the animals vaccinated with the commercial inactivated PRRSV vaccine Progressis ${ }^{\circledR}$ (first experiment), neither the IPMA nor the VN antibody response was influenced before or after challenge with 07 V063. This is in line with the studies by Zuckermann et al. (2007) [24] and Vanhee et al. (2009) [25], where they used the same vaccine and the LV strain as challenge virus: no clear induction of challenge virus-specific (neutralizing) antibodies was observed upon vaccination with the commercial inactivated PRRSV vaccine and only a moderate anamnestic antibody response was observed upon challenge of the vaccinated animals. The apparent limited immunogenicity of this vaccine may relate to the inactivation procedure used, strain variability, antigenic dose, adjuvant, ... Further research is necessary to elucidate this. In the animals vaccinated with the commercial attenuated vaccines, either based on EU- (Porcilis ${ }^{\circledR}$ PRRS) or NA- (Ingelvac ${ }^{\circledR}$ PRRS MLV) type virus, a low or non-detectable $\mathrm{VN}$ antibody response was observed, which is in agreement with the results of Lopez et al. (2004) [33]. None of the attenuated vaccines were able to induce a faster neutralizing antibody response upon challenge. The data obtained in this study have provided the basis for an ongoing field study on the effect of different vaccines at the farm level, more specifically on the effects of vaccination of sows on the passive immunity transferred to piglets.

In the 07 V063- and 08 V194-challenged groups vaccinated with a BEI-inactivated vaccine homologous to the challenge virus, a correlation was seen between the induction of virus-specific neutralizing antibodies and reduction in viremia, indicating that $\mathrm{VN}$ antibodies may contribute to protection against the virus. However, the induction of homologous $\mathrm{VN}$ antibodies was not sufficient to completely protect the animals, as it still permitted the development of a viremia post-challenge that lasted at least one week. Possibly, higher VN antibody titers are needed at the time of challenge to offer full protection against the high dose of virus used to infect the animals. Administration of a heterologous BEI- 
inactivated vaccine was not sufficient to significantly reduce viremia in the animals upon challenge. Since the BEI-inactivated vaccines used in this study induced antibodies that could neutralize the homologous as well as the heterologous challenge virus in in vitro seroneutralization assays, it was somewhat surprising that these vaccines could only limit viremia under the homologous challenge conditions, and not when the heterologous challenge virus was used. The exact reason behind this remains currently unknown, but several possible explanations suggest themselves. For instance, it is possible that induction of virus-specific neutralizing antibodies is not sufficient and that BEI-inactivated PRRSV vaccines must promote other immune mechanisms (e.g. via cross-presentation to T-cells) to provide a significant degree of protection upon challenge. On the other hand, it can be speculated that, although the vaccine-induced antibodies can bind and neutralize the homologous and heterologous challenge virus to a similar extent in in vitro $\mathrm{SN}$ assays, they recognize the homologous virus with a higher affinity. Affinity differences may explain a reduced binding and neutralization of heterologous virus in vivo, as the binding conditions for ( $\mathrm{VN})$ antibodies are likely more stringent in vivo than in the in vitro $\mathrm{SN}$ assays. Under homologous challenge conditions, the antibodies have undergone optimal challenge virusspecific affinity maturation, while this is not the case under heterologous challenge conditions. In theory, the presence of vaccine-induced antibodies that cross-react with a heterologous challenge virus may even prevent the selection of high-affinity (VN) antibodies against this challenge virus (original antigenic sin). Clearly, this matter requires further investigation in the future. Despite the absence of a clear challenge virus-specific VN antibody response, the commercial attenuated vaccines do provide a partial virological protection, roughly similar to the protection provided by the autogenous BEIinactivated vaccines. This observation points towards a significant role of other attenuated vaccine-induced immune mechanisms (e.g. cell-mediated immunity) in the protection against PRRSV infection $[24,31,38]$. Vaccination with the commercial inactivated vaccine Progres$\mathrm{sis}^{\circledR}$ did not induce $\mathrm{VN}$ antibodies and neither did it provide any degree of protection upon challenge.

Considering the similar efficacy of the attenuated vaccines against both challenge isolates used in this study, it can be questioned whether the use of autogenous inactivated vaccines is advantageous over the use of the current attenuated vaccines. However, while the efficacy of the attenuated vaccines against new virus variants can be unpredictable, our data demonstrate that an (adaptable) autogenous BEI-inactivated vaccine can provide a more or less standardized, predictable degree of protection against a specific virus variant, which may prove useful in case virus variants emerge that escape the immunity induced by the attenuated vaccines. In the near future, additional research will be conducted to further substantiate this. Also, although the production of autogenous inactivated vaccines as described in this study may appear too elaborate and costly (virus isolation, adaptation to cell culture, high dose needed,...), further optimization of the production process should make future use of these vaccines more feasible.

\section{Conclusions}

The current study assessed the protective capacity of different experimental and commercial vaccines against challenge with two recent PRRSV field isolates. Experimental BEI-inactivated vaccines based on these field isolates significantly shortened viremia upon homologous challenge. Despite the concerns regarding the efficacy of the commercial attenuated vaccines used on the farms where the field isolates were obtained, use of commercial attenuated vaccines resulted in a similar reduction of the viremic phase. In contrast, the experimental BEIinactivated vaccines did not significantly reduce viremia upon heterologous challenge and the commercial inactivated vaccine had no apparent effect.

While the BEI-inactivated vaccines (both homologous and heterologous) induced challenge virus-specific neutralizing antibodies, this was not the case for the commercial inactivated and attenuated vaccines. The results illustrate that the capacity of a vaccine to induce challenge virus-specific neutralizing antibodies does not necessarily correlate with protection against the challenge virus and vice versa, suggesting that not only vaccineinduced antibodies, but also other vaccine-induced immune mechanisms can contribute to PRRSV-specific protective immunity.

The observation that homologous BEI-inactivated vaccines can provide a more or less standardized, predictable degree of protection against a specific virus variant suggests that such vaccines may prove useful in case virus variants emerge that escape the immunity induced by the attenuated vaccines. Future research will allow optimization and simplification of the production process of the adaptable BEI-inactivated vaccines and give further insights into the mechanisms of protection induced by these vaccines.

\section{Methods}

\section{Cells and viruses}

Porcine alveolar macrophages (PAMs) were derived from 3-week-old (just weaned) piglets, purchased from a PRRSV- and Mycoplasma Hyopneumoniae-negative farm. After isolation, the morphology of PAMs was checked visually via light microscopy. No specific tests 
were performed to detect PCV2. PAMs and MARC-145 cells were cultivated as described before [39].

The Belgian PRRSV isolates used in this study originated from two farms showing clinical signs compatible with PRRS in sows or growing pigs. The two isolates were randomly selected from 19 isolates obtained between 2007 and 2010. At the moment of sampling, sows of both herds were vaccinated with a EU-genotype attenuated vaccine (Porcilis ${ }^{\circledR}$ PRRS). PRRSV isolate 07 V063 was isolated from fetal tissue by inoculating tissue suspensions on PAM. This isolate has been used in recent studies by Karniychuk et al. $(2011 ; 2012)$ [40,41], describing viral, clinical and pathological data. Similarly, the 08 V194 isolate was obtained by inoculating the serum of 14-week-old piglets on PAM. Both isolates were also adapted to MARC-145 cells by repeated passages. For challenge, macrophage-grown stocks were prepared of the isolates 07 V063 ( $2^{\text {nd }}$ passage on PAM) and 08 V194 $\left(5^{\text {th }}\right.$ passage on PAM).

For vaccine preparation, MARC-145 cell culture supernatants of $07 \mathrm{V063}\left(2^{\text {nd }}\right.$ passage on PAM +2 passages on MARC-145), 08 V194 ( $2^{\text {nd }}$ passage on PAM +4 passages on MARC-145) and LV ( $2^{\text {nd }}$ passage on PAM +5 passages on MARC-145), were purified via ultracentrifugation as previously described by Vanhee et al. (2009) [25].

\section{Genome sequencing and phylogenetic analysis}

To determine if adaptation to the MARC-145 cell line resulted in mutations in the structural ORFs, ORF2-7 of MARC-145-grown 07 V063, 08 V194 and LV were sequenced and compared with those of original macrophage-grown 07 V063, 08 V194 and LV. Sequencing was performed as described before [42]. Nucleotide sequences were submitted to Genbank under accession numbers [GenBank: GU737264] (07 V063) and [GenBank: GU737265] (08 V194).

Amino acid (aa) sequences were subsequently derived and analysed using CLC Free workbench 4. The aa sequences of all structural proteins of MARC-145-grown 07 V063, 08 V194 and LV were 100\% identical to those of the corresponding proteins of original macrophagegrown virus. The clear difference in aa sequence between both 07 V063 and 08 V194 and the Porcilis ${ }^{\circledR}$ PRRS strain allowed their classification as EU wild-type viruses that are not of vaccine origin.

\section{Virus inactivation and quality control}

Purified virus (07 V063, 08 V194 and LV) was suspended in RPMI 1640 (Invitrogen) to a titer of $10^{8} \mathrm{TCID}_{50} / \mathrm{mL}$. Subsequently, the virus was inactivated using BEI as described before [25], and inactivated virus was stored at $-70^{\circ} \mathrm{C}$. To confirm that all virus was completely inactivated, a complete vaccine dose of 07 V063, 08 V194 and LV was inoculated on MARC-145 cells and subsequently passaged twice. As a positive control, MARC-145 cells were inoculated with $1 \mathrm{~mL}$ of non-inactivated $07 \mathrm{V063}$, 08 V194 or LV. The MARC-145 cells were routinely checked for cytopathic effect (CPE) and ultimately stained for the PRRSV nucleocapsid protein via an immunoperoxidase staining using monoclonal antibody 13E2 [43]. No CPE or positive nucleocapsid staining was detected in cells that were inoculated with inactivated virus, while clear $\mathrm{CPE}$ and nucleocapsid staining were observed in cell cultures that were inoculated with non-inactivated virus.

Since conservation of entry of inactivated virus may serve as a quality control for the preservation of antigenic properties, the effect of BEI inactivation on virus attachment and internalization into macrophages was examined as described previously $[25,44]$. Non-inactivated virus suspensions were included as positive controls. The entry experiment showed that the binding and internalization kinetics of all BEI-inactivated virus stocks are similar to those observed for the non-inactivated virus stocks.

\section{Pigs and experimental design}

Sixty-seven four-week-old piglets were purchased from a PRRSV-negative farm and their PRRSV-seronegative status was confirmed by IPMA upon arrival. The animals were housed in isolation units with HEPA-filtered air and kept during 7 days to allow adaptation to the new conditions. Two experiments were performed (Table 1). All animal experiments were approved by the local ethical committee of the Faculty of Veterinary Medicine, Ghent University.

\section{Vaccination experiment with PRRSV isolate 07 V063}

Thirty-six pigs were randomly divided into six groups. An oil-in-water $(\mathrm{o} / \mathrm{w})$ diluent, normally used in the commercial pseudorabies virus vaccine Suvaxyn Aujeszky (Fort Dodge Animal Health), was used as an adjuvant and is further referred to as o/w Suvaxyn. A first group (group CON, $n=6$ pigs) served as a mock-vaccinated control group and received $1 \mathrm{~mL}$ RPMI 1640 in $1 \mathrm{~mL}$ o/ w Suvaxyn intramuscularly at 5 and 9 weeks of age. Three other groups were vaccinated twice intramuscularly at 5 (primo vaccination) and 9 (booster vaccination) weeks of age. Group 07 V063i ( $n=6$ pigs) was vaccinated with $1 \mathrm{~mL}$ BEI-inactivated MARC-145-grown 07 V063 $\left(10^{8} \mathrm{TCID}_{50}\right)$ in $1 \mathrm{~mL}$ o/w Suvaxyn and group LVi ( $n=6$ pigs) was vaccinated with $1 \mathrm{~mL}$ BEIinactivated MARC-145-grown LV $\left(10^{8} \mathrm{TCID}_{50}\right)$ in $1 \mathrm{~mL}$ o/w Suvaxyn. Group PROi ( $n=6$ pigs) received $2 \mathrm{~mL}$ of a commercial European type inactivated PRRSV vaccine (Progressis ${ }^{\circledR}$, Merial, strain P120: min 2,5 log IF Units). Groups PORatt ( $n=6$ pigs) and INGatt ( $n=6$ pigs) were vaccinated once intramuscularly with the European type attenuated vaccine $\left(\right.$ Porcilis $^{\circledR}$ PRRS, Intervet, $10^{4}$ $\mathrm{TCID}_{50} / 2 \mathrm{~mL}$ ) and the American type attenuated 


\begin{tabular}{|c|c|c|c|}
\hline Group & Vaccination & $\begin{array}{l}\text { Age in } \\
\text { weeks }\end{array}$ & $\begin{array}{l}\text { Challenge strain } \\
\text { (13 weeks) }\end{array}$ \\
\hline \multicolumn{4}{|l|}{$\begin{array}{l}\text { Experiment } \\
1(\mathrm{n})\end{array}$} \\
\hline $\operatorname{CON}(6)$ & Mock & 5 and 9 & 07 V063 \\
\hline 07 V063i (6) & BEl-inactivated 07 V063 & 5 and 9 & 07 V063 \\
\hline LVi (6) & BEl-inactivated LV & 5 and 9 & 07 V063 \\
\hline PROi (6) & Progressis $^{\circledR}$ & 5 and 9 & 07 V063 \\
\hline PORatt (6) & Porcilis ${ }^{\circledR}$ PRRS & 7 & 07 V063 \\
\hline INGatt (6) & Ingelvac ${ }^{\circledR}$ PRRS & 7 & 07 V063 \\
\hline \multicolumn{4}{|l|}{$\begin{array}{l}\text { Experiment } \\
2(n)\end{array}$} \\
\hline CON2 (7) & Mock & 5 and 9 & 08 V194 \\
\hline 08 V194i (6) & BEl-inactivated 08 V194 & 5 and 9 & 08 V194 \\
\hline LVi2 (6) & BEl-inactivated LV & 5 and 9 & 08 V194 \\
\hline 07 V063i2 (6) & BEl-inactivated 07 V063 & 5 and 9 & 08 V194 \\
\hline PORatt2 (6) & Porcilis ${ }^{\circledR}$ PRRS & 7 & 08 V194 \\
\hline
\end{tabular}

vaccine (Ingelvac ${ }^{\circledR}$ PRRS MLV, Boehringer Ingelheim, $10^{4.9} \mathrm{TCID}_{50} / 2 \mathrm{~mL}$ ), respectively, at the age of 7 weeks. At 13 weeks of age, all pigs were challenged intranasally with PRRSV 07 V063 $\left(10^{6} \mathrm{TCID}_{50}\right)$ in phosphate buffered saline (PBS) $(2,5 \mathrm{ml}$ per nostril). Blood samples were taken by jugular venipuncture weekly after (primo) vaccination and at $0,1,3,5,7,10,14,21,28,35$ and $42 \mathrm{dpc}$. Serum was collected and stored at $-70^{\circ} \mathrm{C}$. Serum samples for IPMA and VN antibody detection were incubated for $30 \mathrm{~min}$ at $56^{\circ} \mathrm{C}$ prior to freezing.

\section{Vaccination experiment with PRRSV isolate 08 V194}

In a second experiment, 31 piglets were randomly assigned to five treatment groups. Group CON2 $(n=7$ pigs) served as a mock-vaccinated control group and received $1 \mathrm{~mL}$ RPMI 1640 in $1 \mathrm{~mL}$ o/w Suvaxyn intramuscularly at 5 and 9 weeks of age. Three other groups were vaccinated twice intramuscularly at 5 (primo vaccination) and 9 (booster vaccination) weeks of age. Group 08 V194i ( $n=6$ pigs) was vaccinated with $1 \mathrm{~mL}$ BEI-inactivated MARC-145-grown 08 V194 $\left(10^{8}\right.$ TCID $\left._{50}\right)$ in $1 \mathrm{~mL}$ o/w Suvaxyn, group LVi2 ( $n=6$ pigs) was vaccinated with $1 \mathrm{~mL}$ BEI-inactivated MARC-145-grown LV $\left(10^{8} \mathrm{TCID}_{50}\right)$ in $1 \mathrm{~mL} \mathrm{o} / \mathrm{w}$ Suvaxyn and group 07 V063i2 ( $n=6$ pigs) was vaccinated with $1 \mathrm{~mL}$ BEIinactivated MARC-145-grown 07 V063 $\left(10^{8} \mathrm{TCID}_{50}\right)$ in $1 \mathrm{~mL} \mathrm{o} / \mathrm{w}$ Suvaxyn. At 7 weeks of age, pigs of group PORatt2 ( $n=6$ pigs) were vaccinated intramuscularly with Porcilis ${ }^{\circledR}$ PRRS at a dose of $10^{4} \mathrm{TCID}_{50}$ per pig. PRRSV-isolate 08 V194 at a dose of $10^{6} \mathrm{TCID}_{50}$ was used to inoculate all pigs intranasally $(2,5 \mathrm{ml}$ per nostril) at the age of 13 weeks. The same experimental design was used as in the first experiment.

\section{Virus titration and serological examinations}

Virus titers in serum were determined by virus titration on PAM following a standard procedure [32]. 24-h cultivated PAM were inoculated with 10 -fold dilution series of the serum samples. 72 hours post inoculation, cells were fixed and an immunoperoxidase staining with monoclonal antibody 13E2 against the PRRSV nucleocapsid protein was performed to visualize infection in the cells [43]. The titers were calculated as described by Reed and Muench (1938) [45] and expressed as TCID $50 /$ $\mathrm{mL}$. To check the sensitivity of the PAM, all cell batches were assayed in virus titrations using a PRRSV stock (LV) with a known virus titer.

Serum samples were examined for the presence of PRRSV-specific antibodies using an IPMA as described by Labarque et al. (2000) [32]. To detect antibodies against 07 V063 ( $1^{\text {st }}$ experiment), an IPMA was performed on 07 V063-infected MARC-145 cells. To detect antibodies against 08 V194 ( $2^{\text {nd }}$ experiment), an IPMA was performed on 08 V194-infected MARC-145 cells. $\mathrm{VN}$ antibodies were detected by seroneutralization assays on MARC-145 cells using the respective PRRSV challenge isolate. Each serum sample was tested in duplicate. Briefly, serum samples were twofold serially diluted and an equal volume of a PRRSV 07 V063 ( $2^{\text {nd }}$ passage on PAM +2 passages on MARC-145) or 08 V194 $\left(2^{\text {nd }}\right.$ passage on PAM +4 passages on MARC145) suspension (titer $2 \times 10^{3} \mathrm{TCID}_{50} / \mathrm{mL}$ ) was added to each dilution. After mixing, the plates were incubated at $37^{\circ} \mathrm{C}$ for $1 \mathrm{~h}$ and $50 \mu \mathrm{l}$ of the mixture was subsequently transferred to confluent monolayers of MARC-145 cells in 96-well plates. Cells were screened for 7 days after inoculation and the neutralization titer of the sera was recorded as the reciprocal of the highest dilution that inhibited CPE in $50 \%$ of the inoculated wells. To check the sensitivity to PRRSV infection of different passages of MARC-145 cells, control titrations using PRRSV stocks (isolate $07 \mathrm{~V} 063$ and isolate $08 \mathrm{V194}$ ) with a known virus titer were performed in parallel with each neutralization assay.

\section{Statistical analysis}

Antibody titers and virus titers were analyzed by Kruskall-Wallis test, followed by Dunn's multiple comparisons test to determine significant differences with the control groups at different time points. Samples, that tested negative in IPMA, VN or virus isolation were consequently given a numerical value of 0.0. A twotailed Fisher's exact test was used to determine significant differences between the number of viremic animals in the vaccinated groups and the control groups at 
different time points. An overall $p$ value of 0.05 was taken as the level of statistical significance. All statistical analyses were performed using GraphPad Prism version 5.0a (GraphPad Software, San Diego, California, USA).

\section{Competing interests}

The authors declare that they have no competing interests.

\section{Authors' contributions}

MFG carried out the isolation of both PRRSV isolates, performed the vaccination studies and statistical analyses. He wrote the manuscript and participated in the study design. MV participated in both vaccination studies and helped writing the manuscript. WVB participated in the second experiment and helped to write the manuscript. JVD carried out sequencing and phylogenetic analyses. UUK participated in the first experiment. HJN conceived the study, coordinated the work and helped in writing the manuscript. All authors read and approved the final manuscript.

\section{Acknowledgements}

The authors would like to thank Chantal Vanmaercke, Carine Boone, Chris Bracke, Nele Dennequin, Melanie Bauwens, Geert Opsomer and Bart Ellebaut for their highly appreciated and excellent technical assistance. The authors are grateful to Dominiek Maes and Tamara Vandersmissen for searching and providing farms with PRRSV-related disorders. This work was funded by the Federal Public Service Health, Food chain safety and Environment (RT Theme 7 - Acron. PORRS) and the European Union (Seventh Framework Programme; Project No. 245141).

\section{Author details}

'Laboratory of Virology, Faculty of Veterinary Medicine, Ghent University, Salisburylaan 133, Merelbeke 9820, Belgium. ${ }^{2}$ Department of Health Care and Biotechnology, KATHO Catholic University College of South-West Flanders, Wilgenstraat 32, Roeselare 8800, Belgium.

Received: 11 April 2012 Accepted: 23 September 2012

Published: 3 October 2012

\section{References}

1. Christianson WT, Collins JE, Benfield DA, Harris L, Gorcyca DE, Chladek DW, Morrison RB, Joo HS: Experimental reproduction of swine infertility and respiratory syndrome in pregnant sows. Am J Vet Res 1992, 53:485-488.

2. Christianson WT, Choi CS, Collins JE, Molitor TW, Morrison RB, Joo HS: Pathogenesis of porcine reproductive and respiratory syndrome virus infection in mid-gestation sows and fetuses. Can J Vet Res 1993, 57:262-268.

3. Lager KM, Mengeling WL: Pathogenesis of in utero infection in porcine fetuses with porcine reproductive and respiratory syndrome virus. Can J Vet Res 1995, 59:187-192

4. Mengeling WL, Lager KM, Vorwald AC: Temporal characterization of transplacental infection of porcine fetuses with porcine reproductive and respiratory syndrome virus. Am J Vet Res 1994, 55:1391-1398.

5. Rossow KD, Bautista EM, Goyal SM, Molitor TW, Murtaugh MP, Morrison RB, Benfield DA, Collins JE: Experimental porcine reproductive and respiratory syndrome virus infection in one-, four-, and 10-week-old pigs. J Vet Diagn Invest 1994, 6:3-12.

6. Terpstra C, Wensvoort G, Pol JM: Experimental reproduction of porcine epidemic abortion and respiratory syndrome (mystery swine disease) by infection with Lelystad virus: Koch's postulates fulfilled. Vet Q 1991, 13:131-136.

7. Van Gucht S, Labarque G, Van Reeth K: The combination of PRRS virus and bacterial endotoxin as a model for multifactorial respiratory disease in pigs. Vet Immunol Immunopathol 2004, 102:165-178.

8. Neumann EJ, Kliebenstein JB, Johnson CD, Mabry JW, Bush EJ, Seitzinger AH, Green AL, Zimmerman JJ: Assessment of the economic impact of porcine reproductive and respiratory syndrome on swine production in the United States. J Am Vet Med Assoc 2005, 227:385-392.

9. Wensvoort G, Terpstra C, Pol JM, ter Laak EA, Bloemraad M, de Kluyver EP, Kragten C, van Buiten L, den Besten A, Wagenaar F, et al: Mystery swine disease in The Netherlands: the isolation of Lelystad virus. Vet Q 1991, 13:121-130
10. Allende R, Lewis TL, Lu Z, Rock DL, Kutish GF, Ali A, Doster AR, Osorio FA: North American and European porcine reproductive and respiratory syndrome viruses differ in non-structural protein coding regions. J Gen Virol 1999, 80:307-315.

11. Forsberg R, Storgaard T, Nielsen HS, Oleksiewicz MB, Cordioli P, Sala G, Hein J, Bøtner A: The genetic diversity of European type PRRSV is similar to that of the North American type but is geographically skewed within Europe. Virology 2002, 299:38-47.

12. Mateu E, Martín M, Vidal D: Genetic diversity and phylogenetic analysis of glycoprotein 5 of European-type porcine reproductive and respiratory virus strains in Spain. $J$ Gen Virol 2003, 84:529-534.

13. Nelsen CJ, Murtaugh MP, Faaberg KS: Porcine reproductive and respiratory syndrome virus comparison: divergent evolution on two continents. J Virol 1999, 73:270-280.

14. Díaz I, Gimeno M, Darwich L, Navarro N, Kuzemtseva L, López S, Galindo I, Segalés J, Martín M, Pujols J, Mateu E: Characterization of homologous and heterologous adaptive immune responses in porcine reproductive and respiratory syndrome virus infection. Vet Res 2012, 43:30.

15. Martínez-Lobo FJ, Díez-Fuertes F, Simarro I, Castro JM, Prieto C: Porcine Reproductive and Respiratory Syndrome Virus isolates differ in their susceptibility to neutralization. Vaccine 2011, 29:6928-6940.

16. Meng XJ: Heterogeneity of porcine reproductive and respiratory syndrome virus: implications for current vaccine efficacy and future vaccine development. Vet Microbiol 2000, 12:309-329.

17. Opriessnig T, Baker RB, Halbur PG: Use of an experimental model to test the efficacy of planned exposure to live porcine reproductive and respiratory syndrome virus. Clin Vaccine Immunol 2007, 14:1572-1577.

18. Labarque G, Reeth KV, Nauwynck H, Drexler C, Van Gucht S, Pensaert M: Impact of genetic diversity of European-type porcine reproductive and respiratory syndrome virus strains on vaccine efficacy. Vaccine 2004 22:4183-4190.

19. Dewey CE, Wilson S, Buck P, Leyenaar JK: The reproductive performance of sows after PRRS vaccination depends on stage of gestation. Prev Vet Med 1999, 11:233-241.

20. Mengeling WL, Vorwald AC, Lager KM, Clouser DF, Wesley RD: Identification and clinical assessment of suspected vaccine-related field strains of porcine reproductive and respiratory syndrome virus. Am J Vet Res 1999, 60:334-340.

21. Nielsen TL, Nielsen J, Have P, Baekbo P, Hoff-Jorgensen R, B $\varphi$ tner A: Examination of virus shedding in semen from vaccinated and from previously infected boars after experimental challenge with porcine reproductive and respiratory syndrome virus. Vet Microbiol 1997, 54:101-112.

22. Nielsen HS, Oleksiewicz MB, Forsberg R, Stadejek T, B $\varphi$ tner A, Storgaard T: Reversion of a live porcine reproductive and respiratory syndrome virus vaccine investigated by parallel mutations. J Gen Virol 2001, 82:1263-1272.

23. Nilubol D, Platt KB, Halbur PG, Torremorell M, Harris DL: The effect of a killed porcine reproductive and respiratory syndrome virus (PRRSV) vaccine treatment on virus shedding in previously PRRSV infected pigs. Vet Microbiol 2004, 102:11-18.

24. Zuckermann FA, Garcia EA, Luque ID, Christopher-Hennings J, Doster A, Brito M, Osorio F: Assessment of the efficacy of commercial porcine reproductive and respiratory syndrome virus (PRRSV) vaccines based on measurement of serologic response, frequency of gamma-IFN-producing cells and virological parameters of protection upon challenge. Vet Microbiol 2007, 123:69-85.

25. Vanhee M, Delputte PL, Delrue I, Geldhof MF, Nauwynck HJ: Development of an experimental inactivated PRRSV vaccine that induces virusneutralizing antibodies. Vet Res 2009, 40:63.

26. Thanawongnuwech R, Suradhat S: Taming PRRSV: Revisiting the control strategies and vaccine design. Virus Res 2010, 154:133-140.

27. Scortti M, Prieto C, Alvarez E, Simarro I, Castro JM: Failure of an inactivated vaccine against porcine reproductive and respiratory syndrome to protect gilts against a heterologous challenge with PRRSV. Vet Rec 2007, 161:809-813.

28. Cano JP, Dee SA, Murtaugh MP, Pijoan C: Impact of a modified-live porcine reproductive and respiratory syndrome virus vaccine intervention on a population of pigs infected with a heterologous isolate. Vaccine 2007, 25:4382-4391.

29. Scortti M, Prieto C, Simarro I, Castro JM: Reproductive performance of gilts following vaccination and subsequent heterologous challenge with 
European strains of porcine reproductive and respiratory syndrome virus. Theriogenology 2006, 66:1884-1893.

30. Nechvatalova K, Kudlackova H, Leva L, Babickova K, Faldyna M: Transfer of humoral and cell-mediated immunity via colstrum in pigs. Vet Immunol Immunopathol 2011, 142:95-100.

31. Diaz I, Darwich L, Pappaterra G, Pujols J, Mateu E: Different European-type vaccines against porcine reproductive and respiratory syndrome virus have different immunological properties and confer different protection to pigs. Virology 2006, 351:249-259.

32. Labarque GG, Nauwynck HJ, Van Reeth K, Pensaert MB: Effect of cellular changes and onset of humoral immunity on the replication of porcine reproductive and respiratory syndrome virus in the lungs of pigs. J Gen Virol 2000, 81:1327-1334

33. Lopez OJ, Osorio FA: Role of neutralizing antibodies in PRRSV protective immunity. Vet Immunol Immunopathol 2004, 102:155-163.

34. Lopez OJ, Oliveira MF, Garcia EA, Kwon BJ, Doster A, Osorio FA: Protection against porcine reproductive and respiratory syndrome virus (PRRSV) infection through passive transfer of PRRSV-neutralizing antibodies is dose dependent. Clin Vaccine Immunol 2007, 14:269-275.

35. Osorio FA, Galeota JA, Nelson E, Brodersen B, Doster A, Wills R, et al: Passive transfer of virus-specific antibodies confers protection against reproductive failure induced by a virulent strain of porcine reproductive and respiratory syndrome virus and establishes sterilizing immunity. Virology 2002, 302:9-20.

36. Okuda Y, Kuroda M, Ono M, Chikata S, Shibata I: Efficacy of vaccination with porcine reproductive and respiratory syndrome virus following challenges with field isolates in Japan. J Vet Med Sci 2008, 70:1017-1025.

37. Kim WI, Yoon KJ: Molecular assessment of the role of envelopeassociated structural proteins in cross neutralization among different PRRS viruses. Virus Genes 2008, 37:380-391.

38. Charerntantanakul W, Platt R, Johnson W, Roof M, Vaughn E, Roth JA: Immune responses and protection by vaccine and various vaccine adjuvant candidates to virulent porcine reproductive and respiratory syndrome virus. Vet Immunol Immunopathol 2006, 109:99-115.

39. Delrue I: Development of a new inactivated porcine reproductive and respiratory syndrome virus (PRRSV) vaccine. PhD thesis. Ghent University, Department of Virology, Parasitology and Immunology; 2010.

40. Karniychuk UU, Saha D, Vanhee M, Geldhof MF, Cornillie P, Caij AB, De Regge N, Nauwynck HJ: Impact of a novel inactivated PRRSV vaccine on virus replication and virus-induced pathology in fetal implantation sites and foetuses upon challenge. Theriogenology 2012, 78:1527-1537.

41. Karniychuk UU, Saha D, Geldhof M, Vanhee M, Cornillie P, Van den Broeck W, Nauwynck HJ: Porcine reproductive and respiratory syndrome virus (PRRSV) causes apoptosis during its replication in fetal implantation sites. Microb Pathog 2011, 51(3):194-202.

42. Delrue I, Van Gorp H, Van Doorsselaere J, Delputte PL, Nauwynck HJ: Susceptible cell lines for the production of porcine reproductive and respiratory syndrome virus by stable transfection of sialoadhesin and CD163. BMC Biotechnol 2010, 10:48

43. Van Breedam W, Costers S, Vanhee M, Geldhof MF, Verbeeck M, Rodriguez Gomez I, Van Doorsselaere J, Gagnon CA, Nauwynck H: PRRSV-specific mAbs: supporting diagnostics and providing new insights into the antigenic properties of the virus. Vet Immunol Immunopathol 2011 141:246-257.

44. Delrue I, Delputte PL, Nauwynck HJ: Assessing the functionality of viral entry-associated domains of porcine reproductive and respiratory syndrome virus during inactivation procedures, a potential tool to optimize inactivated vaccines. Vet Res 2009, 40:62.

45. Reed $\sqcup$, Muench $H$ : A simple method of estimating fifty percent endpoints. Am J Hyg 1938, 27:493-497.

doi:10.1186/1746-6148-8-182

Cite this article as: Geldhof et al: Comparison of the efficacy of autogenous inactivated Porcine Reproductive and Respiratory Syndrome Virus (PRRSV) vaccines with that of commercial vaccines against homologous and heterologous challenges. BMC Veterinary Research 2012 8:182.

\section{Submit your next manuscript to BioMed Central and take full advantage of:}

- Convenient online submission

- Thorough peer review

- No space constraints or color figure charges

- Immediate publication on acceptance

- Inclusion in PubMed, CAS, Scopus and Google Scholar

- Research which is freely available for redistribution

Submit your manuscript at www.biomedcentral.com/submit
() Biomed Central 